\title{
Leprosy and American cutaneous leishmaniasis coinfection*
}

\author{
Larissa Mondadori Mercadante ${ }^{1}$ \\ Elisangela Samartin Pegas ${ }^{2}$
}

\author{
Marcel Alex Soares dos Santos ${ }^{1}$ \\ Bogdana Victória Kadunc ${ }^{1}$
}

DOI: http:/ / dx.doi.org/10.1590/abd1806-4841.20186698

\begin{abstract}
Brazil is a country with a high prevalence of infectious diseases such as leprosy and leishmaniasis. However, coinfection of these diseases is still poorly understood. We report a case of a patient who presented with lepromatous leprosy and cutaneous-mucosal leishmaniasis at the same period. After clinical, laboratory, and histopathological diagnosis, the treatment was introduced and the patient showed important clinical improvement. He was followed in our outpatient clinic. Both pathologies play an important role in the immune system. Depending on the immune response profile of the host, diseases may present themselves in different ways. In this case, the patient showed a divergent immune response for each disease. We hypothesized that this response is specific for each pathogen.
\end{abstract}

Keywords: Leishmaniasis; Leprosy; Immunity

\section{INTRODUCTION}

Lepromatous leprosy (LL) and American cutaneous leishmaniasis (ACL) are diseases caused by intracellular microorganisms that affect the mucocutaneous tissue, with a chronic inflammatory response and a broad clinical spectrum. ${ }^{1}$ They are of great importance in world public health and are highly prevalent in tropical countries, especially in Brazil. ${ }^{1}$ Despite this, only a few cases have been reported with the association of both diseases. ${ }^{2}$

LL is a chronic infectious disease caused by a bacillus known as Mycobacterium leprae. ${ }^{1,3}$ According to the WHO, more than 200,000 new cases are reported per year worldwide. In the Americas, Brazil holds $90 \%$ of the cases. ${ }^{1}$ The clinical picture initially involves peripheral skin and nerves, with a possible evolution to deformities and physical disabilities. ${ }^{3}$

Unlike LL, ACL is not contagious. ${ }^{1,4}$ It is caused by a protozoan parasite of the genus Leishmania, transmitted by sandflies. ${ }^{4}$ Worldwide, its incidence is estimated at 0.7-1.2 million new cases annually. ${ }^{2}$ In Brazil, it is in geographical expansion, with peaks of incidence every five years, distributed in all the states. It is characterized by the presence of a single painless nodule that can progress to multiple papules or normochromic or erythematous nodules, macules, ulcers, and infiltrative plaques. ${ }^{2}$

The present report aims to describe a case of coinfection of LL and ACL, a picture with few reports in the literature.

\section{CASE REPORT}

We report the case of a 46-year-old male rural worker who was diagnosed with multibacillary leprosy approximately two years before. The disease had been classified as borderline virchowian. The patient reported treatment with multibacillary multidrug therapy (MDT-MB) for 24 months due to the persistence of the lesions after 12 months. The patient reported subcutaneous nodules on the trunk and limbs, accompanied by neuropathic pain in the ulnar nerve and paresthesia on the lower limbs for 1 month. He also reported the appearance of a left-sided ulcer 2 years before, which

Received on 08.11.2016.

Approved by the Advisory Board and accepted for publication on 14.02.2017.

* Work performed at Pontifícia Universidade Católica de Campinas (PUC -Campinas) - Campinas (SP), Brazil.

Financial support: None.

Conflict of interest: None.

1 Dermatology Service at Pontifícia Universidade Católica de Campinas (PUC -Campinas) - Campinas (SP), Brazil.

2 Leprosy Outpatient Service at Pontifícia Universidade Católica de Campinas (PUC -Campinas) - Campinas (SP), Brazil.

MAILING ADDRESS:

Larissa Mondadori Mercadante

E-mail: larissa_40@yahoo.com.br 


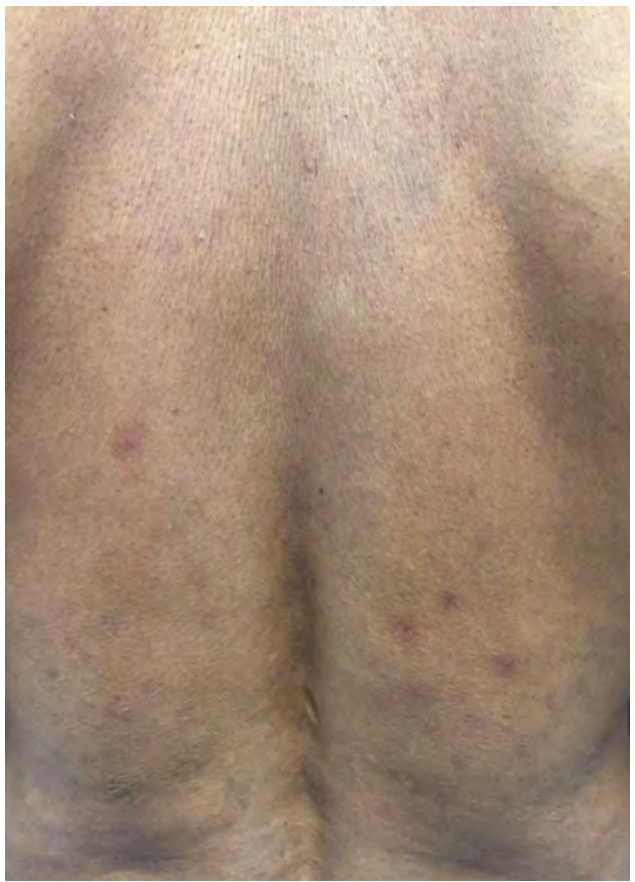

Figure 1:

Irregular and poorly delimited brownish macules and spots on the back

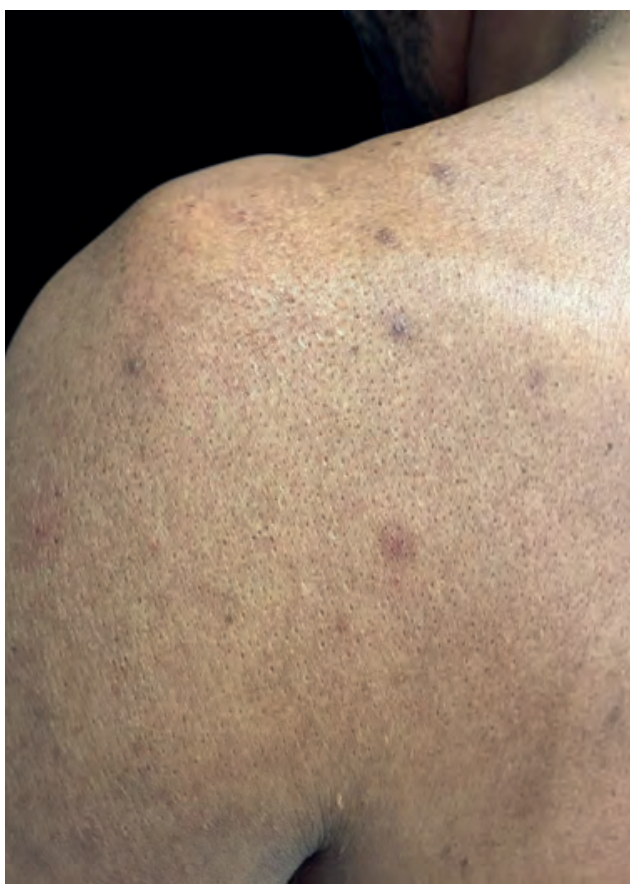

Figure 2:

Brown colored erythematous nodules of 0.5 $1.0 \mathrm{~cm}$ in size located on the proximal part of the upper limbs

he attributed to repeated traumas at work. Dermatological examination revealed nodules of $0.5-1 \mathrm{~cm}$ on the upper limbs and poorly delimited irregular brownish spots on the trunk, back (Figures 1 and $2)$, and lower limbs, in addition to an ulcer on the left knee with an infiltrated, raised and keratotic border with granular erythematous floor, of approximately $7 \mathrm{~cm}$ in size (Figure 3 ).

We investigated the diagnostic hypotheses of type II reaction of leprosy and ACL. We initiated treatment with thalidomide $100 \mathrm{mg} /$ daily and prednisone $40 \mathrm{mg} /$ daily for the reaction, and requested PCR and culture for leishmaniasis, with a positive result

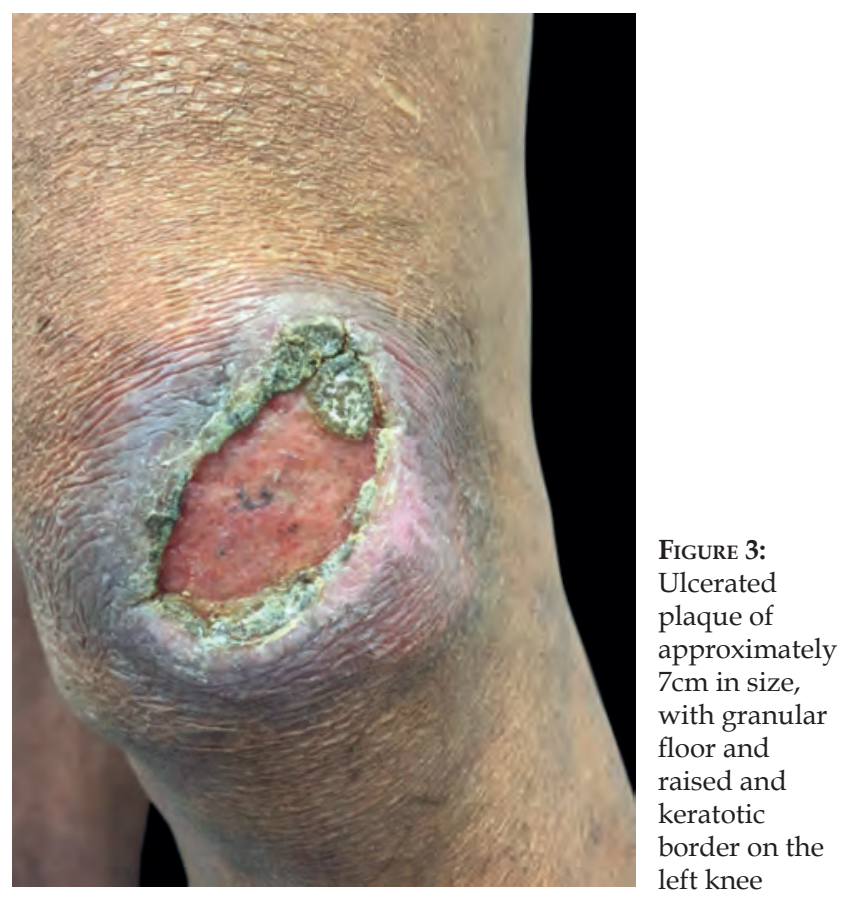

for Leishmania brasiliensis. Ultrasound biopsy showed diffuse interstitial chronic dermatitis with lymphohistiocytic infiltrate, which revealed, in the cytoplasm of some histiocytes, rounded structures with morphology compatible with amastigotes of Leishmania, confirming the diagnosis of cutaneous leishmaniasis (Figures 4 and 5). A pentavalent antimonial was then introduced at a dose of $15 \mathrm{mg} /$ $\mathrm{kg} /$ day, intravenously, with significant clinical improvement of the two diseases. The patient is currently being followed up at the dermatology outpatient clinic.

\section{DISCUSSION}

The diseases described in the present study have a fundamental immunological role and their characteristics will depend on the intensity of the cell-mediated specific immunity expressed by the subject. Both may have an immune response mediated by $\mathrm{T}$ helper 1 (Th1) or T helper 2 (Th2) cells. ${ }^{5}$

Both Hansen's bacilli and protozoa of the genus Leishmania, upon entering the organism, are phagocytosed by macrophages. In patients with hyperergic response, such as tuberculoid leprosy and localized cutaneous or mucosal leishmaniasis, macrophages release cytokines that act on the Th1 lymphocyte subpopulation, which in turn produces IL-2, IFN- $\gamma$, and TNF- $\alpha$, triggering a cellular immune response. In an individual in a state of anergy, such as lepromatous leprosy and anergic cutaneous leishmaniasis patients, the cytokines produced by macrophages act on the Th2 subpopulation, which produces IL-4, IL-5, IL-10, and IL-13, which suppress macrophage activity and stimulate B lymphocytes and mast cells, thus configuring the humoral immune response..$^{5-7}$ Thus, individuals with a Th1 immune profile are more resistant to infection because they present a more intense and effective cellular immune response, whereas individuals with Th2 immune profile are more susceptible..$^{5-7}$ 


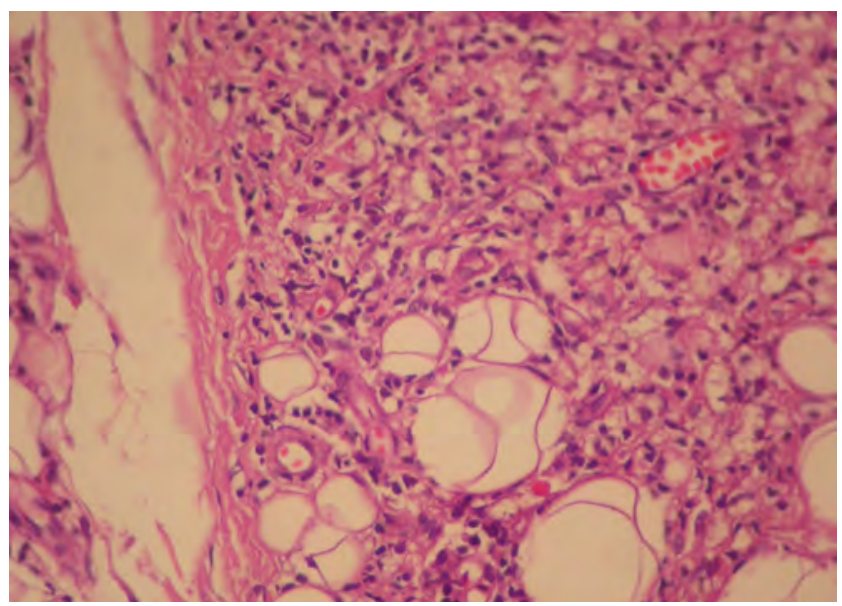

FIGURE 4: Diffuse interstitial chronic dermatitis, with lymphohistiocytic infiltrate (Hematoxylin \& eosin, X10)

In the present case, the patient presented with concomitant lepromatous leprosy and localized cutaneous leishmaniasis with different immune responses to each disease (anergic to the former and hyperergic to the latter) in the same period, suggesting that his immunological defect is specific for each infecting microorganism. ${ }^{8}$

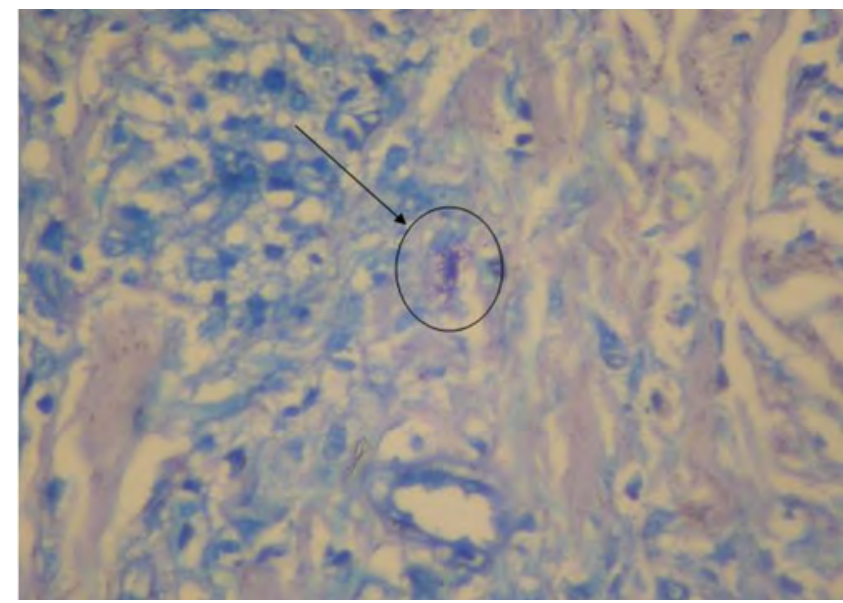

Figure 5: Presence of structures compatible with Leishmania in the cytoplasm of histiocytes (PAS, X40)

The association between LL and ACL is still little known, partially because this association is uncommon. Additional studies are needed to better explain the immunological mechanisms during the co-infection, aiming at the best treatment and avoiding the appearance of physical incapacities and sequelae that may be caused by these diseases. $\square$

\section{REFERENCES}

1. Costa JML, Saldanha ACR, Melo LS, Silva AR, Ferreira LA, Costa G, et al. Cutaneous leishmaniasis (Cl) associated with leprosy: A new and emerging clinicoepidemiological entity observed in the northeast of Brazil. Gaz méd Bahia 2009;79:95-102.

2. Patrao NA, Bhat RM, Dandekeri S, Kambil SM. Diffuse cutaneous leishmaniasis in coexistence with leprosy. Int J Dermatol. 2015;;54:1402-6.

3. Kamath S, Vaccaro SA, Rea TH, Ochoa MT. Recognizing and managing the immunologic reactions in leprosy. J Am Acad Dermatol. 2014;71:795-803.

4. Murback ND, Hans Filho G, Nascimento RA, Nakazato KR, Dorval ME. Leishmaniose tegumentar americana: estudo clínico, epidemiológico e laboratorial realizado no Hospital Universitário de Campo Grande, Mato Grosso do Sul, Brasil. An Bras Dermatol. 2011;86:55-63.
5. Belda Júnior W, Di Chiacchio N, Criado PR. Tratado de Dermatologia. 2. ed. São Paulo: Ed. Atheneu; 2014.

6. Araujo AR, Portela NC, Feitosa AP, Silva OA, Ximenes RA, Alves LC, et al. Risk factors associated with American cutaneous leishmaniasis in an endemic area of Brazil. Rev Inst Med Trop Sao Paulo. 2016;58:86.

7. Duque MC, Vasconcellos ÉC, Pimentel MI, Lyra MR, Pacheco SJ, Marzochi MC, et al. - Standardization of intralesional meglumine antimoniate treatment for cutaneous leishmaniasis. Rev Soc Bras Med Trop. 2016:49:774-6.

8. Solon AMS, Moreno ACL, Silva AA, Valente NS, Benard G, Criado PR, et al. Coinfecção hanseníase e leis

How to cite this article: Mercadante LM, Santos MAS, Pegas ES, Kadunc BV. Leprosy and American cutaneous leishmaniasis coinfection. An Bras Dermatol. 2018;93(1):123-5. 